\title{
Risk assessment of herbicides compared to other pesticides in Brazil
}

\author{
Caio A. Carbonari ${ }^{*}{ }^{*}$, Edivaldo D. Velini ${ }^{\mathrm{a}}$ (우 \\ a Universidade Estadual Paulista Júlio de Mesquita Filho, Botucatu, SP, Brazil.
}

Abstract: The use of herbicides is essential to preserve the productivity
and efficiency of crops in land use and growth factors. The general public
has questioned the use of herbicides and pesticides, even when used
rationally and following the procedures approved by regulatory agencies.
It is essential to present accurate information about these products' use
and the risk associated with this use in this context. The mean dose and
the Environmental Impact Quotient (EIQ) continuously decreased as a
function of the year of release of new active ingredients with herbicidal
action in Brazil, which indicates that the new products are more efficient

Keywords: Chemical control; EIQ; Pesticides; Risks; Sustainability and present lower risks to the environment, farmworkers and consumers. The mean EIQ for each herbicide application in soybean, maize, sugarcane, and cotton has decreased in Brazil. The proportion of herbicides in the number of applications has decreased compared to other classes of pesticides, except for cotton. The risk of products decreased over time, with continuous reductions in EIQ values per unit of the treated area; the EIQ values determined per production remained stable despite the increased complexity of pest management, which caused an increase in the number of applications.
Journal Information:

ISSN - 2675-9462

Website: http://awsjournal.org

Journal of the Brazilian Weed Science Society

How to cite: Carbonari CA, Velini ED. Risk assessment of herbicides compared to other pesticides in Brazil. Adv Weed Sci. 2021;39:e21202032.

https://doi.org/10.51694/AdvWeedSci/2021;39:00006

Approved by:

Editor in Chief: Anderson Luis Nunes

Associate Editor: Luis Antonio de Avila

Conflict of interest: The authors declare that there is no conflict of interest regarding the publication of this manuscript.

Received: September 4, 2020

Approved: December 3, 2020

* Corresponding author:

<caio.carbonari@unesp.br>

\section{(c) (1)}

This is an open-access article distributed under the terms of the

Creative Commons Attribution License, which permits unrestricted use, distribution, and reproduction in any medium, provided that the original author and source are credited.

Copyright: 2021

\section{Use of pesticides in Brazil and worldwide}

The Brazilian agricultural matrix is one of the most diverse in the world. Brazil produces food and large amounts of fiber, bioenergy, industrial raw materials, and ecosystem services. We must consider this aspect when we analyze the use of pesticides in general. Only a portion of the pesticides is used to produce food that is consumed domestically or exported. Another relevant aspect is that pesticide use analysis requires data normalization per cultivated area or production quantity of all agricultural products, not just food products.

Also, use and consumption cannot be confused. As farmers use pesticides, if there are any residues of these pesticides in food, consumers may ultimately consume pesticides when they consume food. It is important to note that the amount of pesticide applied is not the amount of residue consumed in food. When applied to plants, pesticides are subject to various degradation and dissipation processes, and in general, only a fraction of what is applied reaches the structures of the harvested plants. Consequently, the amounts of pesticides present in agricultural products at harvest represent small fractions of what was applied.

Considering the total value of pesticides sold worldwide, the fact that Brazil is the largest consumer of pesticides worldwide is noteworthy (Figure 1A). On a global scale, data referring to the total expense in acquiring products in different countries or years predominate. Given that it is reasonable to assume that taxation and prices of pesticides vary over time and between countries, it is easy to conclude that this is not the best metric for comparing risks associated with pesticides. Because there is no other information, it is necessary to use metrics that involve commercialization values as indicators of risk associated with pesticide use. However, it is necessary to normalize these data by area cultivated or unit of production.

When we normalize the use of pesticides by dividing it by the cultivated area (Figure 1B), Brazil ranks seventh after Japan, South Korea, Germany, France, Italy, and the United Kingdom. If we compare the consumption rate by the amount of agricultural products produced (Figure $1 C$ ), Brazil ranks $13^{\text {th }}$. These data only consider the Brazilian agricultural area, not considering the pasture area and planted forests, which represent even lower use from the point of view of pesticide use per area or production.

Even normalized information comparing the level of risk associated with pesticide use in different countries should be used cautiously. Amore correct practice uses information that effectively indicates risk, such as the Environmental Impact Quotient (EIQ), which we will discuss in this article. 


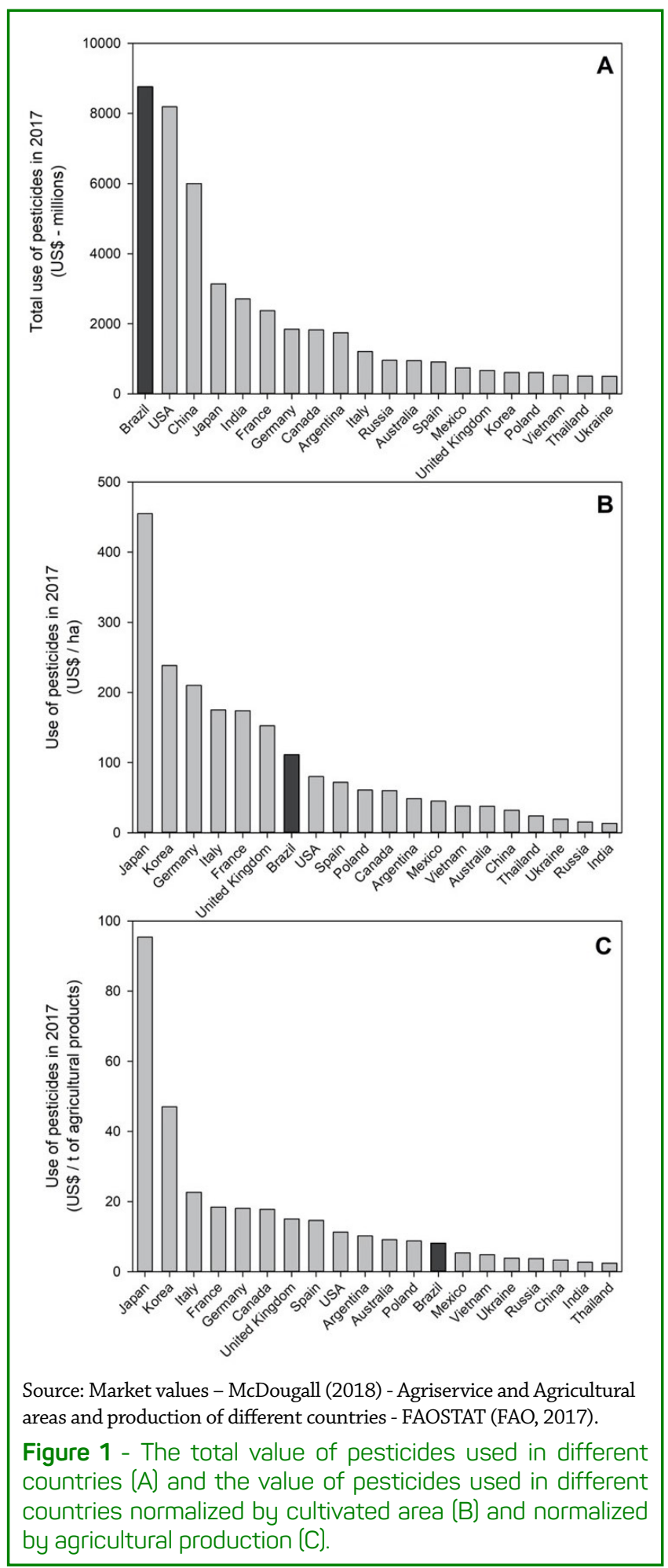

Considering that the recommendation for using the information on pesticides per $\mathrm{g}$ or $\mathrm{kg}$ of active ingredient per unit area has been consolidated, even if it has to be converted into $\mathrm{g}, \mathrm{mL}, \mathrm{kg}$, or $\mathrm{L}$ of a commercial product, information on the use of active ingredients should be prioritized when information on the amount of pesticide used is presented. Taking glyphosate as an example, it is typical to use the amount of acid equivalent per hectare (g a.e. $\mathrm{ha}^{-1}$ ) to define the application rate. The quantities of commercial products or commercialization values should be considered only as indicators and not as exact measurements of the amounts of active ingredients used.

In summary, we should prefer to use information that refers to active ingredients or risk indicators. We should be cautious about using the information on pesticide use based on the amount of commercial products or market values. Before comparing countries, regions, years, or production systems, data must be normalization as discussed above.

2. What is the best risk indicator associated with the use of herbicides and pesticides in general?

The amount of active ingredient used is a good indicator, but we cannot limit ourselves to dealing with pesticide use and not address the most relevant issue, which is the risk associated with pesticide use. When dealing with risk, all caution previously discussed should be maintained. It is noteworthy that risk is not synonymous with hazard. The risk depends on both the hazard and the exposure. In turn, exposure depends on several factors, including dose, number of applications, the time interval between application and harvest, residue half-life (RL50), pesticide dynamics in the plant and the environment, technology, and protective equipment used. Considering this complexity, we need to address the question: "Is there any risk indicator of pesticide use that is accurate, simple to use, and easy to understand?" To date, the best available option is the EIQ proposed by Kovach et al. (1992). This indicator is calculated from a total of 12 pesticide characteristics: skin toxicity, chronic toxicity, systemicity, toxicity to fish, leaching potential, movement potential in the soil surface, toxicity to birds, $50 \%$ degradation time in the soil, toxicity to bees, toxicity to beneficial arthropods and 50\% degradation time on the plant surface. The total EIQ is characteristic of each active ingredient and corresponds to the mean of three other more specific coefficients calculated from subgroups of the cited characteristics: ecological EIQ, worker EIQ, and consumer EIQ. As described by Kovach et al. (1992), the EIQ is calculated as follows:

$$
\begin{aligned}
E I Q=\{[C * & ((D T * 5)+(D T * P))]+\left[\left(\mathrm{C} *\left(\frac{\mathrm{S}+\mathrm{P}}{2}\right) * \mathrm{SY}\right)+\mathrm{L}\right] \\
+ & {\left.\left[(\mathrm{F} * \mathrm{R})+\left(\mathrm{D} *\left(\frac{\mathrm{S}+\mathrm{P}}{2}\right) * 3\right)+(\mathrm{Z} * \mathrm{P} * 3)+(\mathrm{B} * \mathrm{P} * 5)\right]\right\} / 3 }
\end{aligned}
$$

where: $\mathrm{DT}=$ dermal toxicity, $\mathrm{C}=$ chronic toxicity, $\mathrm{SY}=$ systemicity, $\mathrm{F}=$ fish toxicity, $\mathrm{L}=$ leaching potential, $\mathrm{R}=$ surface loss potential, $\mathrm{D}=$ bird toxicity, $\mathrm{S}=$ soil half-life, $\mathrm{Z}=$ bee toxicity, $\mathrm{B}=$ beneficial arthropod toxicity, $\mathrm{P}=$ plant surface half-life.

Kovach et al. (1992) describe the EIQ equation as being divided into three components: 1 - Farm Worker includes C, DT, and P, 2 - Consumer risk includes C, S, P, SY and 3 - 
Ecology includes F, R, D, S, P, Z, and B. Each risk factor in the EIQ can take on one of three possible values; if the risk is considered "low", then a value of 1 is assigned; "medium" risks are assigned a value of 3 , and "high" risks are assigned a value of 5 .

The EIQ values are dimensionless and determined for $1 \mathrm{~kg}$ of the active ingredient. The correct way to compare pesticides is to calculate the EIQ per ha of the application area, multiplying the EIQ by the application rate of active ingredient used in each treatment or using applications that perform the calculation automatically, such as the EIQ Calculator (Cornell, 018). Consequently, two pesticides with the same EIQ value may have completely different risks if the doses expressed in $\mathrm{g}$ or $\mathrm{kg}$ of active ingredient per ha are also different, and pesticides applied at the same dose may have different risks if they have different EIQ coefficients. To calculate the EIQ per ha of cultivation, the EIQ calculated for all pesticide applications per applied area must be added for a crop cycle or year.

The use of EIQ as a risk indicator associated with the use of pesticides offers the following advantages: it considers a complex set of parameters on the hazards and dynamics of pesticides in the agricultural environment; allows separate evaluation of the risks to the environment, workers, and consumers; and considers the rate of active ingredient used per unit area. If there is information about the pesticides and application rates, it is possible to calculate the EIQ per ha treated (sum of all applications), per $\mathrm{kg}$ or $\mathrm{t}$ of the product (sum of EIQ in all applications divided by the amount produced), or for an entire region or country (sum of all values).

An example of the use of EIQ is illustrated in Figure 2 , which shows a continuous reduction in the mean dose of herbicides used in Brazil, indicating that the new products are more efficient and require lower rates of application. The mean rates of application of pesticides in general and herbicides used since 2000 are 12\% and $4 \%$, respectively, of the mean application rate of pesticides and herbicides developed up to the 1970s. In other words, recently approved herbicides in Brazil are safer for the farmer, consumer, and environment and are applied at rates 25 times lower than that of the herbicides developed up to the 1970s (Figure 2B). The reduction of doses and increased efficacy reduced all EIQ components simultaneously (Figure 2).

The information presented in Figure 2 also indicates that the tendency to reduce the average dose of application and the EIQ was maintained in recent decades. When products registered between 1990-1999 and between 2000 to the current year were compared, a reduction in the average dose of all pesticides and herbicides by $29 \%$ and $52 \%$ were observed. Considering all pesticides, the average reductions of Ecological EIQ, Farmworker EIQ, and Consumer EIQ were 28\%, 29\%, and 40\%, respectively, when the same time intervals were compared. For herbicides, the average reductions in EIQ were $42 \%, 40 \%$, and $56 \%$,

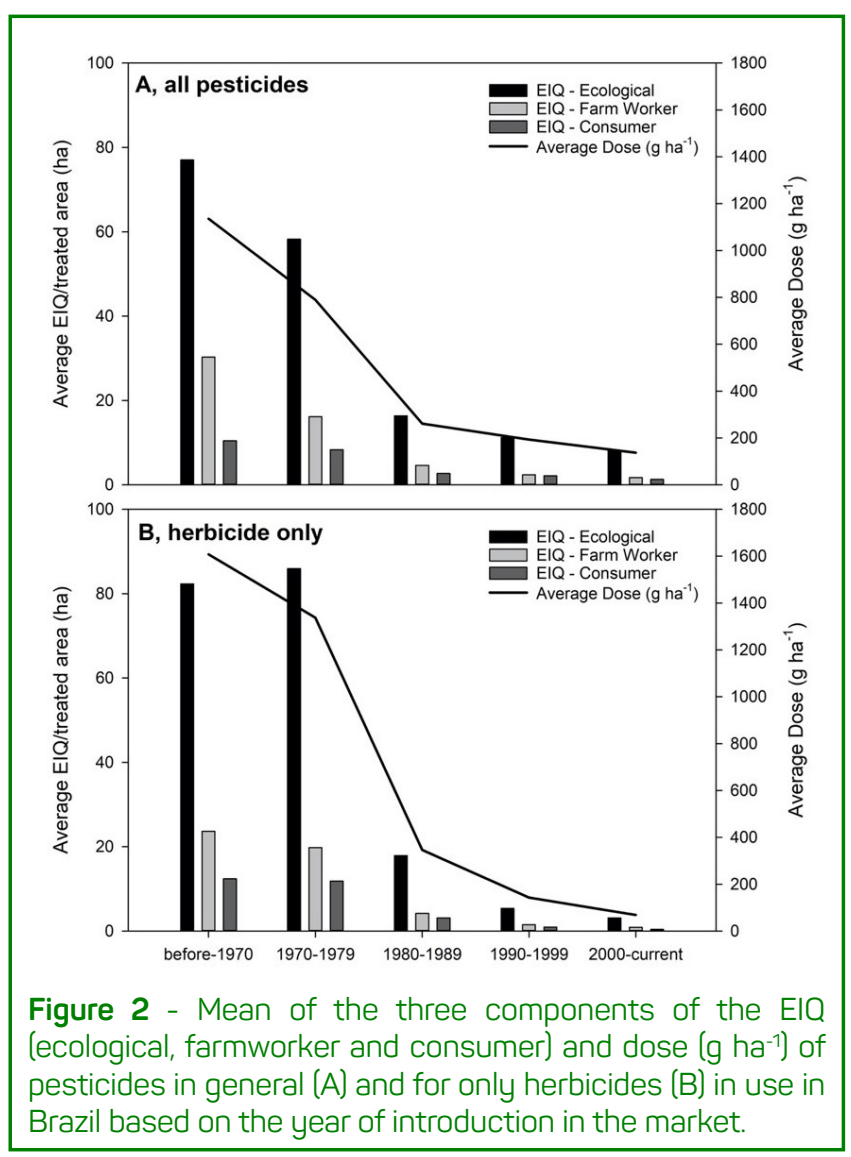

also respectively. Therefore, the tendency to reduce doses and EIQ continues indicating that, on average, the latest products are safer for the environment, farmworkers, and consumers than the older ones.

It is possible to confirm the trends of dose reduction and increased safety of recently developed pesticides and herbicides by analyzing information on these products' use under Brazil's field conditions, as shown in Figure 3. The information presented in this figure refers not to each application but rather to the annual mean of the EIQ values obtained for each commercial product when considering its mean dose and the total applied area, regardless of whether it was used alone or mixed with other pesticides. The continuous reduction in field EIQ and its components are evident in the applications performed from 2002 to 2015. During this period, there were reductions of 51 , 37,34 , and $38 \%$, respectively, for the worker, consumer, environment, and field EIQ values for all pesticides. Specifically, the percentages of reduction were lower for the herbicides, i.e., 17, 22, 13, and $13 \%$, respectively.

As will be discussed in the next section, such reductions were fundamental for the sustainability of our agricultural production and for maintaining the EIQ values expressed per hectare of cultivated area or tonne of production at levels compatible with international standards, even with the increasing cases of resistance and the introduction of new pest species. 


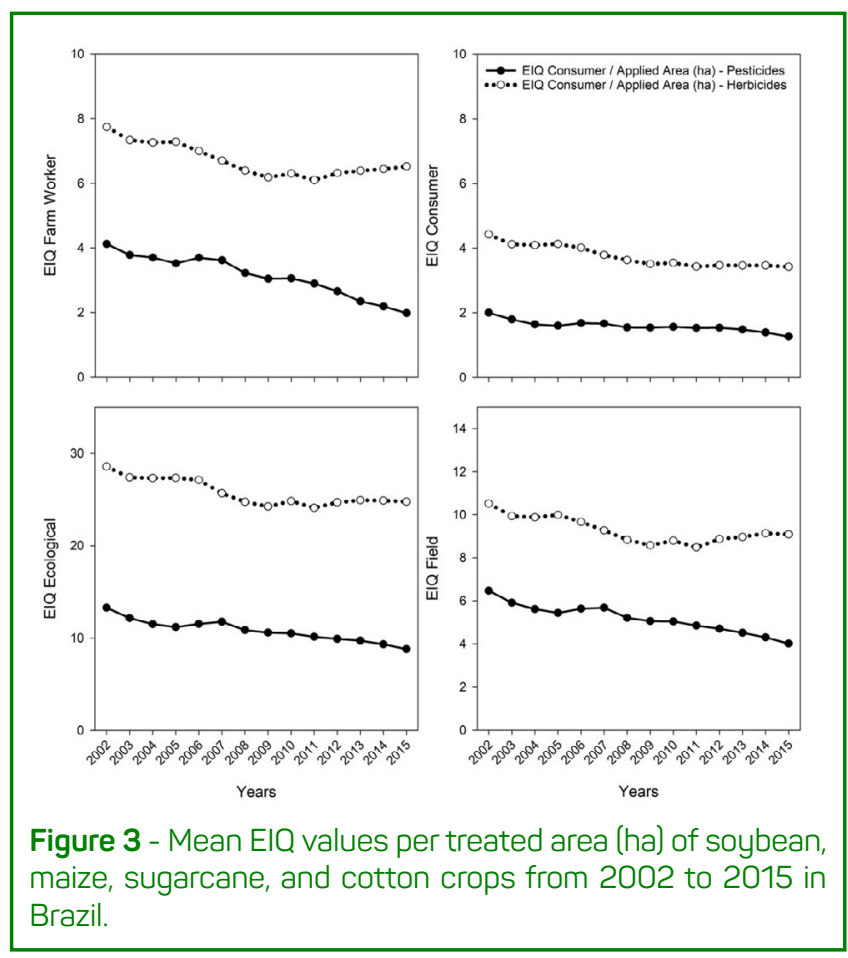

3. Use and values of EIQ associated with herbicides and pesticides in Brazil

For soybean, maize, sugarcane, and cotton, with 36.94 , 18.44, 8.40, and 1.66 million hectares planted in Brazil, respectively (Conab, 2020), there was an increase in the number of herbicide applications per unit area from 2002 to 2015 - except use in soybean, which was stable during this period (Figure 4A). Also, there was a reduction in the percentage of herbicide use during the same period concerning the total number of pesticides used, except for the cotton (Figure 4B). For the number of applications per unit area, the number of commercial products applied, alone or in combination, is considered instead of the number of operations performed.

Despite the increase in the number of herbicide applications to the four crops, the proportion of herbicides concerning the total number of pesticide applications decreased. Although we had experienced an increase in cases of herbicide-resistant weeds, increasing from 11 to 39 between 2002 and 2015 (Heap, 2020), this reduction in the herbicide proportion indicates that problems with the development of resistance and introduction of new insect pests and diseases were further aggravated in Brazil during this period.

By improving the use of pesticides, those involved in production chains can reduce the EIQ values per ha, per ha cultivated, or per production unit (kg or $\mathrm{t}$ ). When we aim to reduce the risks associated with pesticide use, setting targets for EIQ reductions is much more appropriate than reducing the amount spent on pesticide purchases, the number of applications, or the amount of commercial products or active ingredients used. Brookes

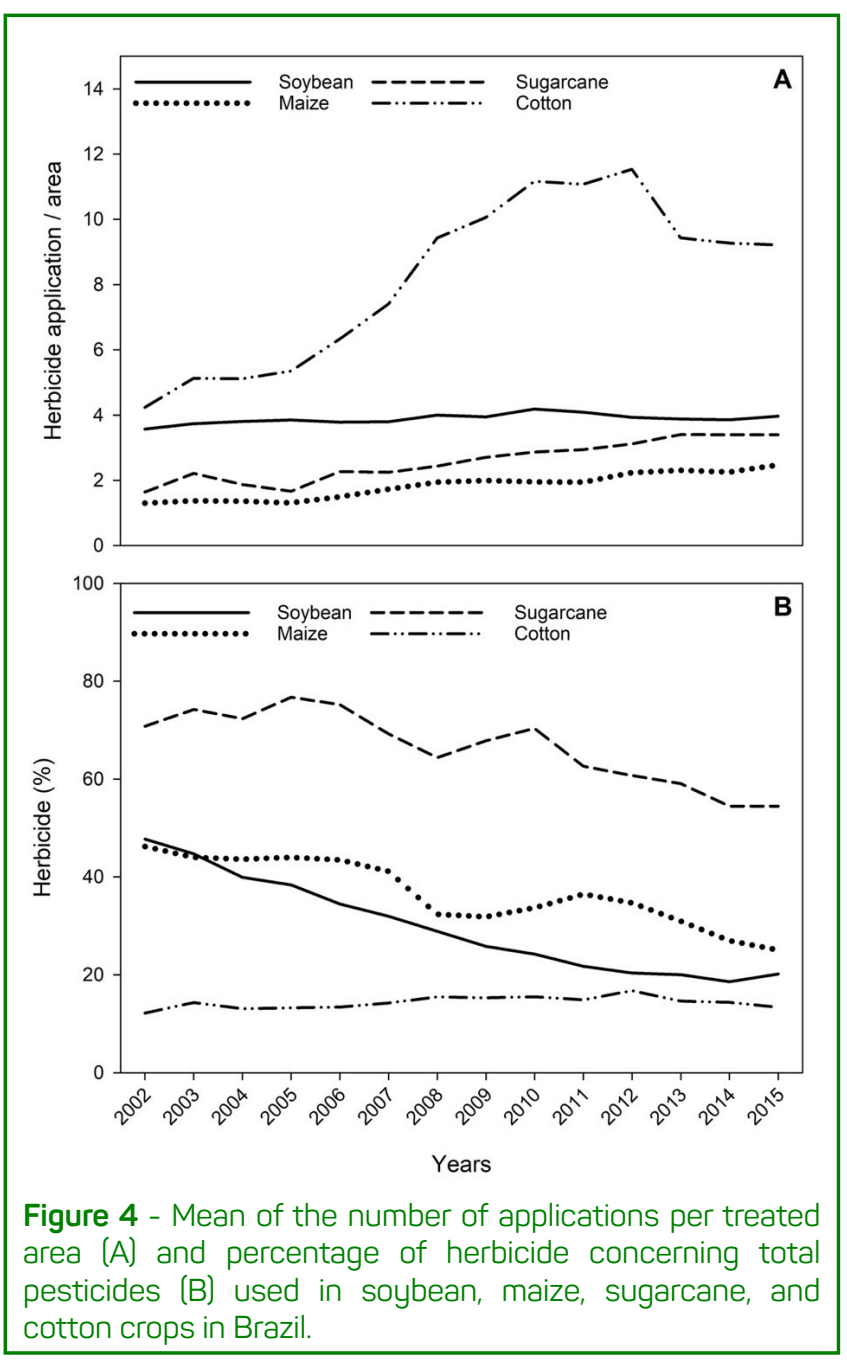

and Barfoot (2017) and FAO (2008) studies are examples of this type of approach.

The overall results of a survey conducted by Brookes and Barfoot (2017) regarding the relationship between the use of genetically modified organisms (GMO), use, and risk associated with pesticides again indicate the difference between pesticide use and the risk associated with its use (Table 1). For the case of herbicide-tolerant soybean, there was an increase of $0.5 \%$ in the amount of active ingredients used but a reduction of $13.9 \%$ in the EIQ units in the evaluated period. There was a reduction in risks even if the amount of pesticides was high. The information regarding EIQ units corresponds to field EIQ values and the number of hectares cultivated with each type of event. The use of herbicide-tolerant or insect-resistant GM maize varieties allowed reductions of $12.7 \%$ and $57.7 \%$ in the number of EIQ corresponding to herbicides and insecticides, respectively.

Table 2 includes the annual means and the means from 2002 to 2015 (soybean, maize, and cotton) or from 2002 to 2014 (sugarcane) for the total EIQ values per unit of cultivated area or per ton of production. These values correspond to the sum of the EIQ of all applications on 
the crops for each cultivation cycle. The information presented indicates that, in general, the EIQ values for the different classes of pesticides and the four crops, expressed per ton of production, have remained stable. This finding indicates a balance between the increase in the number of applications at each cycle (Figure 4A) and the combined benefits of increased productivity in the periods considered $(16 \%, 88 \%, 49 \%$, and $-2 \%$ for soybean, maize, cotton, and sugarcane, respectively, according to Conab, 2020) and of reduced mean rates of application and increased safety of the most recently introduced pesticides in Brazil (Figure 2).
In particular, pesticides in general and herbicides have become progressively safer with continuous reductions in EIQ values per unit of the treated area. Even in the context of the increased complexity of phytosanitary management, which caused an increase in the number of applications, the EIQ values determined per production unit remained stable. The increase in crop productivity and the incorporation of biotechnologies also contributed to this scenario.

Finally, it is essential to analyze the risks associated with pesticide use based on correct and accurate metrics that allow proper conclusions about the safety of products and agricultural production processes.

\begin{tabular}{|c|c|c|c|c|}
\hline \multirow{2}{*}{ Trait } & Active ingredient & Active ingredient & EIQ ha & ElQ ha \\
\hline & Difference in Mkg & Difference in \% & Change in millions & Variation in \% \\
\hline Herbicide-tolerant soybean & 15.3 & 0.5 & -8.112 & -13.9 \\
\hline $\begin{array}{l}\text { Herbicide-tolerant and insect-resistant } \\
\text { soybean }\end{array}$ & -3.6 & -1.4 & -348.000 & -4.3 \\
\hline Herbicide-tolerant maize & -226.0 & -8.4 & -7.315 & -12.7 \\
\hline Insect-resistant maize & -87.1 & -53.3 & -3.891 & -57.7 \\
\hline Herbicide-tolerant cotton & -25.1 & -7.6 & -629.000 & -10.2 \\
\hline Insect-resistant cotton & -268.7 & -29.1 & -11.949 & -31.5 \\
\hline Total & -606.9 & & -32.244 & \\
\hline Mean & & -16.6 & & -21.7 \\
\hline
\end{tabular}

Source: Brookes and Barfoot (2017).

Table 2 - Total field EIQ values in different years and periods in crops with higher use of pesticides in Brazil.

\begin{tabular}{|c|c|c|c|c|c|c|c|}
\hline \multirow[t]{2}{*}{ Crop } & & \multicolumn{2}{|c|}{$\Sigma$ Field ElQ.ha-1 } & \multicolumn{2}{|c|}{$\Sigma$ Field EIQ. ton ${ }^{-1}$} & \multicolumn{2}{|c|}{ Percent of each class } \\
\hline & & 2002-2015 & 2015 & $2002-2015$ & 2015 & 2002-2015 & 2015 \\
\hline \multirow{4}{*}{ Soybean } & Fungicides & 12.50 & 14.76 & 4.39 & 4.92 & 20.60 & 20.70 \\
\hline & Herbicides & 25.02 & 31.47 & 9.13 & 10.49 & 42.78 & 44.12 \\
\hline & Insecticides & 21.41 & 25.10 & 7.81 & 8.37 & 36.62 & 35.18 \\
\hline & Total & 58.48 & 71.32 & 21.33 & 23.79 & 100.00 & 100.00 \\
\hline \multirow{4}{*}{ Maize } & Fungicides & 2.14 & 7.38 & 0.53 & 1.37 & 5.75 & 13.92 \\
\hline & Herbicides & 29.60 & 34.48 & 7.28 & 6.39 & 79.49 & 65.08 \\
\hline & Insecticides & 5.49 & 11.12 & 1.35 & 2.06 & 14.75 & 21.00 \\
\hline & Total & 37.24 & 52.98 & 9.16 & 9.82 & 100.00 & 100.00 \\
\hline \multirow{6}{*}{ Cotton } & Fungicides & 32.08 & 44.47 & 9.22 & 11.10 & 10.83 & 14.15 \\
\hline & Herbicides & 66.72 & 76.27 & 19.16 & 19.04 & 22.52 & 24.26 \\
\hline & Insecticides & 197.47 & 193.60 & 56.72 & 48.32 & 66.65 & 61.59 \\
\hline & Total & 296.27 & 314.33 & 85.10 & 78.45 & 100.00 & 100.00 \\
\hline & & \multicolumn{2}{|c|}{$\Sigma$ Field ElQ.ha-1 } & \multicolumn{2}{|c|}{$\Sigma$ Field ElQ.ton ${ }^{-1}$} & \multicolumn{2}{|c|}{ Percent of each class } \\
\hline & & 2002-2014* & 2014 & 2002-2014* & 2014 & 2002-2014* & 2014 \\
\hline \multirow{4}{*}{ Sugarcane } & Fungicides & 0.11 & 0.50 & 0.0014 & 0.0070 & 0.20 & 0.70 \\
\hline & Herbicides & 44.84 & 56.97 & 0.5739 & 0.7909 & 82.27 & 79.84 \\
\hline & Insecticides & 9.55 & 13.89 & 0.1223 & 0.1928 & 17.53 & 19.46 \\
\hline & Total & 54.51 & 71.36 & 0.6975 & 0.9906 & 100.00 & 100.00 \\
\hline
\end{tabular}

* Specifically, the database used did not include information for 2015 for the sugarcane crop. 


\section{Author' contributions}

Both authors analyzed the data and prepared the manuscript.

\section{Acknowledgments}

The authors thank Dr. Ivana Paula Ferraz Santos de Brito, Dr. Ana Karollyna Alves de Matos and Dr. Maria Lucia Bueno Trindade for data obtaining and processing, and the Kleffmann Group for providing a summary of pesticide use data in Brazil.

\section{Conflicts of interest}

The authors declare no conflict of interest.

\section{References}

Brookes, G., Barfoot, P. G. M. Crops: global socio-economic and environmental impacts 1996- 2015. Dorchester: PG Economics; 2017. 201 p.

College of Agriculture and Life Sciences - Cornell. EIQ calculator. Geneva; 2018. Available from: https://nysipm.cornell.edu/eiq/calculator-field-use-eiq

Companhia Nacional de Abastecimento - Conab. Série histórica das safras. Brasília, DF; 2020. Available from: https://www.conab.gov.br/ info-agro/safras/serie-historica-das-safras

Food and Agriculture Organization of the United Nations - FAO. FAOSTAT Rome; 2017. Available from: http://www.fao.org/faostat/ en/\#data/QC
Food and Agriculture Organization of the United Nations - FAO. IPM ImpactAssessment Series. Guidance document No 2: Guidance on the use of environmental impact quotient in IPM impact assessment. Rome; 2008.

Heap I. The international herbicide-resistant weed database: online. 2020 July 23. Available from: https:www.weedscience.org

Kovach J, Petzoldt C, Degnil J, Tette J. A method to measure the environmental impact of pesticides. NY Food Life Sci Bull. 1992;(130):1-8.

Mcdougall P. Agriservice: industry overview: 2017 market. London: Phillips McDougall, 2018. 